\title{
Genotypic variation in phosphorus acquisition from sparingly soluble $P$ sources is related to root morphology and root exudates in Brassica napus
}

\author{
ZHANG HaiWei ${ }^{1,2}$, HUANG Yu $^{2}$, YE XiangSheng $^{2} \&$ XU FangSen ${ }^{1,2 *}$ \\ ${ }^{1}$ National Key Laboratory of Crop Genetic Improvement, Huazhong Agricultural University, Wuhan 430070, China; \\ ${ }^{2}$ Key Laboratory of Subtropical Agriculture and Environment, Ministry of Agriculture, \\ Huazhong Agricultural University, Wuhan 430070, China
}

Received February 8, 2011; accepted November 9, 2011

\begin{abstract}
Genotypic variations in the adaptive response to low-phosphorus (P) stress and P-uptake efficiency have been widely reported in many crops. We conducted a pot experiment to evaluate the P-acquisition ability of two rapeseed (Brassica napus) genotypes supplied with two sparingly soluble sources of $\mathrm{P}, \mathrm{Al}-\mathrm{P}$ and Fe-P. Then, the root morphology, proton concentrations, and carboxylate content were investigated in a solution experiment to examine the genotypic difference in P-acquisition efficiency. Both genotypes produced greater biomass and accumulated more $\mathrm{P}$ when supplied with Al-P than when supplied with Fe-P. The P-efficient genotype 102 showed a significantly greater ability to deplete sparingly soluble $\mathrm{P}$ from the rhizosphere soil because of its greater biomass and higher $\mathrm{P}$ uptake compared with those of the P-inefficient genotype 105. In the solution experiment, the P-efficient genotype under low-P conditions developed dominant root morphological traits, and it showed more intensive rhizosphere acidification because of greater $\mathrm{H}^{+}$efflux, higher $\mathrm{H}^{+}$-ATPase activity, and greater exudation of carboxylates than the P-inefficient genotype. Thus, a combination of morphological and physiological mechanisms contributed to the genotypic variation in the utilization of different sparingly soluble $\mathrm{P}$ sources in $B$. napus.
\end{abstract}

Brassica napus, sparingly soluble $\mathbf{P}$, genotypic variation, root morphology, $\mathrm{H}^{+}$and carboxylate exudation

Citation: Zhang H W, Huang Y, Ye X S, et al. Genotypic variation in phosphorus acquisition from sparingly soluble P sources is related to root morphology and root exudates in Brassica napus. Sci China Life Sci, 2011, 54: 1134-1142, doi: 10.1007/s11427-011-4254-y

Phosphorus (P) is one of the essential mineral nutrients required for plant growth, but it is one of the most immobile and inaccessible nutrients present in soils [1]. Low availability of $\mathrm{P}$ limits plant growth, metabolism, and production all over the world. This is particularly true of soils that are characterized by strong adsorption of $\mathrm{PO}_{4}^{3-}$ onto $\mathrm{Ca}, \mathrm{Al}$, and Fe oxides. Root-induced physiological and biochemical modifications of the rhizosphere may be involved in the mobilization and exploitation of sparingly soluble P sources in P-deficient soils. Such modifications include rhizosphere acidification, root exudation of organic anions, modification

*Corresponding author (email: fangsenxu@ mail.hzau.edu.cn) of root morphology, upregulation of ion transporters, and symbiotic associations with mycorrhizal fungi [2-4]. Genotypic differences in the adaptability to low-P stress and in P-uptake efficiency have been widely reported in many crops [5-7].

Root morphology is a key factor related to $\mathrm{P}$ acquisition in plants. The contribution of root morphology to P uptake has been reported for many plant species [8,9]. Rhizosphere acidification may play an important role in mobilizing phosphate from calcium phosphates [10]. Changes in $\mathrm{pH}$ in the rhizosphere can arise from protons or bicarbonate ions that are excreted by roots to counterbalance a net excess of cations or anions entering the roots $[11,12]$. Carboxylate 
exudation, which sometimes results in rhizosphere acidification, is also an effective strategy to increase $\mathrm{P}$ uptake from sparingly soluble phosphate sources [3,13]. In addition, in some species, the carboxylate composition and concentration in root exudates varies depending on the forms of $\mathrm{P}$ sources in the soil [14]. Under low-P conditions, roots of rapeseed can actively extrude protons. This proton extrusion leads to soil acidification in the rhizosphere and the dissolution of sparingly soluble phosphate $[3,12,15]$, probably resulting from increased $\mathrm{H}^{+}$-ATPase activity in the root plasma membrane [16].

Brassica napus, also known as rapeseed, plays an important role in human nutrition all over the world, especially in China. It is one of the main oil crops with a high nutritional and economic value. Studies on the P-utilization efficiency of rapeseed are critical for the rational application of phosphate fertilizers for agricultural production in low-P soils. Previous studies have shown that, compared to onion and tomato, rapeseed is better able to acquire $\mathrm{P}$ from sparingly available forms such as Ca-P, Al-P, and Fe-P [17]. Recently, we reported that the P-efficient genotype 102 grew better and accumulated more $\mathrm{P}$ than the P-inefficient genotype 105 in acidic soil with low $\mathrm{P}$ availability [18]. However, the adaptive mechanisms of rapeseed to low-P stress are not well understood, and there have been few integrated studies on genotypic differences in root morphology and rhizosphere processes related to the ability to accumulate $\mathrm{P}$ from sparingly soluble $\mathrm{P}$ sources. The aims of the present study were to determine genotypic differences in the ability to utilize sparingly soluble phosphates in B. napus, and to study the roles of root morphology and root exudates in $\mathrm{P}$ uptake. The results of this study advance our understanding of the physiological mechanisms of $\mathrm{P}$ efficiency. We investigated various rhizosphere properties such as available $\mathrm{P}$, sparingly soluble inorganic $\mathrm{P}$, and rhizosphere soil $\mathrm{pH}$, to assess their roles in plant growth. We also investigated genotypic differences in root morphology, carboxylates exudation, and protons fluxed by roots to understand the differences in P-acquisition efficiency.

\section{Materials and methods}

\subsection{Plant materials}

We used two rapeseed genotypes, 102 (P-efficient) and 105 (P-inefficient), which were screened from 149 recombined inbred lines (F9) derived from a cross between the P-efficient cultivar 97081 and the P-inefficient cultivar 97009 in low-P soil.

\subsection{Pot experiments}

We used low-P eluvial soil (20-cm depth) collected from Shizi Mountain on the campus of Huazhong Agricultural
University, China. The soil properties were as follows: $\mathrm{pH}$ in water of $6.5(1: 2.5 \mathrm{w} / \mathrm{w}$ soil to water ratio), organic matter content of $0.6 \mathrm{~g} \mathrm{~kg}^{-1}$, total nitrogen content of $0.85 \mathrm{~g}$ $\mathrm{kg}^{-1}$, total phosphate content of $0.21 \mathrm{~g} \mathrm{~kg}^{-1}$, and available phosphate content of $1.78 \mathrm{mg} \mathrm{kg}$. The pot experiment consisted of four $\mathrm{P}$ treatments with four replicates in a greenhouse maintained at $18-26^{\circ} \mathrm{C}$ and $70 \%-85 \%$ relative humidity (RH). Five kilograms of air-dried and sieved (2 $\mathrm{mm}$ ) soil was mixed uniformly and divided into two portions: One contained no $\mathrm{P}(0)$ and the other was supplemented with $31 \mathrm{mg} \mathrm{P} \mathrm{kg}^{-1}$ soil in the form of $\mathrm{AlPO}_{4}$ (Al-P), $\mathrm{FePO}_{4}(\mathrm{Fe}-\mathrm{P})$, and $\mathrm{KH}_{2} \mathrm{PO}_{4}(\mathrm{~K}-\mathrm{P})$. The soil was placed in black plastic pots lined with polyethylene bags. All other nutrients were dissolved in water and applied to each pot. The compositions of nutrients were as follows (all values in $\mathrm{mg} \mathrm{kg}^{-1}$ soil): N, 200; K, 166; Mg, 50; Ca, 140; B, 0.2; and Mo, 0.1. All pots were watered and kept for 2 weeks in the greenhouse to reach a nutrient balance in the soil before sowing. Ten seeds of two genotypes were sown directly in the soil and covered with a small amount of fine soil on the surface of the pots to prevent evaporation. The seedlings were thinned to six plants per pot after 1 week. The pots were watered daily to $70 \%$ of field capacity and re-randomized weekly.

Plants were harvested after $45 \mathrm{~d}$ growth, and their shoot fresh weights were recorded. Soil samples were taken from the rhizosphere (close to the roots) with a special soil auger and were air-dried to determine $\mathrm{pH}$, available $\mathrm{P}$ concentration, and inorganic $\mathrm{P}$ fraction. Intact plant roots adhering to the soil were taken from the pots and washed carefully to minimize root damage. The shoot and roots of each plant were dried at $65^{\circ} \mathrm{C}$ for $72 \mathrm{~h}$, weighed, and then ground to a fine powder in a stainless steel ball mill. The powder was digested in concentrated $\mathrm{H}_{2} \mathrm{SO}_{4}$ and $\mathrm{HClO}_{4}$ for total $\mathrm{P}$ determination by the Westerman vanadomolybdate method [19]. The available $\mathrm{P}$ in the soil was determined using the Bray and Kurtz [20] method, and Pi fractions (Al-P, Fe-P and Ca-P) were estimated by the Peterson and Corey method [21].

\subsection{Solution culture experiment}

The solution culture experiment was conducted at Huazhong Agricultural University, China. The seedlings were maintained in a growth chamber under the following controlled climatic conditions: $60 \%-75 \% \mathrm{RH}, 25 / 18^{\circ} \mathrm{C}$ $(16 / 8 \mathrm{~h})$ day/night temperature, and average daytime photosynthetically active radiation of $400 \mu \mathrm{mol} \mathrm{m} \mathrm{m}^{-2} \mathrm{~s}^{-1}$. The germinated seeds were sown on gauze and grown for $5 \mathrm{~d}$ with distilled water only. Uniform seedlings were transferred to 5-L plastic pots containing nutrient solution with the following composition: $\mathrm{Ca}\left(\mathrm{NO}_{3}\right)_{2}\left(4 \mathrm{mmol} \mathrm{L}{ }^{-1}\right), \mathrm{KNO}_{3}$

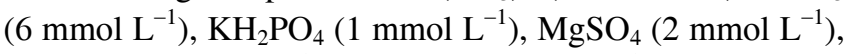
$\mathrm{H}_{3} \mathrm{BO}_{3}\left(46 \mu \mathrm{mol} \mathrm{L}{ }^{-1}\right), \mathrm{MnCl}_{2}\left(9 \mu \mathrm{mol} \mathrm{L}{ }^{-1}\right), \mathrm{ZnSO}_{4}(0.7$ $\left.\mu \mathrm{mol} \mathrm{L}{ }^{-1}\right), \mathrm{CuSO}_{4}\left(0.3 \mu \mathrm{mol} \mathrm{L}{ }^{-1}\right),\left(\mathrm{NH}_{4}\right)_{6} \mathrm{Mo}_{7} \mathrm{O}_{24}(0.02$ 
$\left.\mu \mathrm{mol} \mathrm{L} \mathrm{L}^{-1}\right)$, and EDTA-Fe $\left(50 \mu \mathrm{mol} \mathrm{L}{ }^{-1}\right)$. Three $\mathrm{P}$ treatments were used in this experiment: (i) low $\mathrm{P}\left(5 \mu \mathrm{mol} \mathrm{L} \mathrm{L}^{-1} \mathrm{P}\right)$, (ii) high $\mathrm{P}\left(1 \mathrm{mmol} \mathrm{L}{ }^{-1} \mathrm{P}\right)$, and (iii) no $\mathrm{P}$. After $14 \mathrm{~d}$ growth in the high-P treatment, the seedlings were transferred to nutrient solution without $\mathrm{P}$. The nutrient solution was refreshed every $3 \mathrm{~d}$, and the $\mathrm{pH}$ was adjusted to 5.8 every day.

\subsection{Determination and in situ visualization of fluxed $\mathrm{H}^{+}$ and $\mathrm{H}^{+}$-ATPase activity from roots}

At $18 \mathrm{~d}$ after transplanting, five seedlings per treatment were carefully removed from the low-P and high-P solutions, and the root morphological parameters were estimated by a root scanner and the WINRhizo optical scanner-based image analysis system. At the same time, the capacity of the roots to release protons and their $\mathrm{H}^{+}$-ATPase activity were determined by the methods of M'Sehli et al. [22] and Shen et al. [23], respectively. An in situ visualization technology, as described by Li et al. [24] and Yan et al. [16], was used to estimate the difference in rhizosphere acidification of both genotypes.

\subsection{Determination of carboxylates}

Carboxylates were collected based on the method described by Ishikawa et al. [25]. At $19 \mathrm{~d}$ after transplanting, roots of nine seedlings were washed with deionized water and then immersed in $250 \mathrm{~mL}$ of aerated solution with $0.2 \mathrm{mmol} \mathrm{L}^{-1}$ $\mathrm{CaCl}_{2}$ (pH 5.3) for $6 \mathrm{~h}$ before collecting the root exudates of each plant for carboxylate measurement. The collected solution was passed through a cation exchange column containing $4 \mathrm{~g}$ cation-exchange resin and then through an anion exchange column containing $2 \mathrm{~g}$ anion-exchange anion resin. The carboxylates retained in the anion exchange resins were then eluted with 2 mol L ${ }^{-1}$ hydrochloric acid. The eluent was concentrated to dryness under reduced pressure at $45^{\circ} \mathrm{C}$ using a rotary evaporator, and the residue was re-dissolved in $1 \mathrm{~mL}$ of ultra-pure water and filtered through a $0.45-\mu \mathrm{m}$ filter. The carboxylates were detected by HPLC (Agilent 1200, America; equipped with a C18 250×4.6 mm $(5 \mu \mathrm{m})$ ion-exclusion column, Alltima, America).

\subsection{Statistical analyses}

Data were analyzed using ANOVA tests with SPSS software. Significance was assigned at $P<0.05$ with an LSD test. All values represent the mean of three or four replicates \pm the standard error of the mean.

\section{Results}

\subsection{Plant growth and $P$ uptake in the pot experiment}

The shoot and root dry weights of two rapeseed genotypes were greatest when plants were supplied with K-P, as compared with those of plants supplied with Fe-P or Al-P, which were in turn significantly greater than those of plants grown under the no-P treatment (Figure 1). For the two sparingly soluble $\mathrm{P}$ treatments, the shoot and root dry weights of the seedlings supplied with Al-P were greater than those of the seedlings supplied with Fe-P, regardless of the genotype. There were significant genotypic differences in shoot and root dry weights under the Al-P treatment, especially in root dry weight, which was 1.6 times greater in the P-efficient genotype 102 than in the P-inefficient genotype 105 . There were no significant genotypic differences in shoot and root dry weights under the Fe-P treatment (Figure 1).

Tissue $\mathrm{P}$ accumulation was significantly affected by $\mathrm{P}$ sources. $\mathrm{P}$ accumulation in both the shoots and roots of both genotypes was greatest in plants supplied with K-P, followed by those supplied with Al-P, Fe-P, and no P (Figure 2 ). Consistent with the dry weight, there was significantly greater $\mathrm{P}$ accumulation in both genotypes in the Al-P treatment than in the Fe-P treatment $(P<0.05)$. $\mathrm{P}$ uptake by the P-efficient genotype 102 was significantly greater than that by the P-inefficient genotype 105 under the Al-P treatment but not under the Fe-P treatment $(P<0.05)$ (Figure 2).

\subsection{Rhizosphere pH}

After $45 \mathrm{~d}$ growth, soil $\mathrm{pH}$ in the rhizosphere of both genotypes supplied with sparingly soluble $\mathrm{P}$ sources (Al-P and Fe-P) decreased significantly compared with that of plants

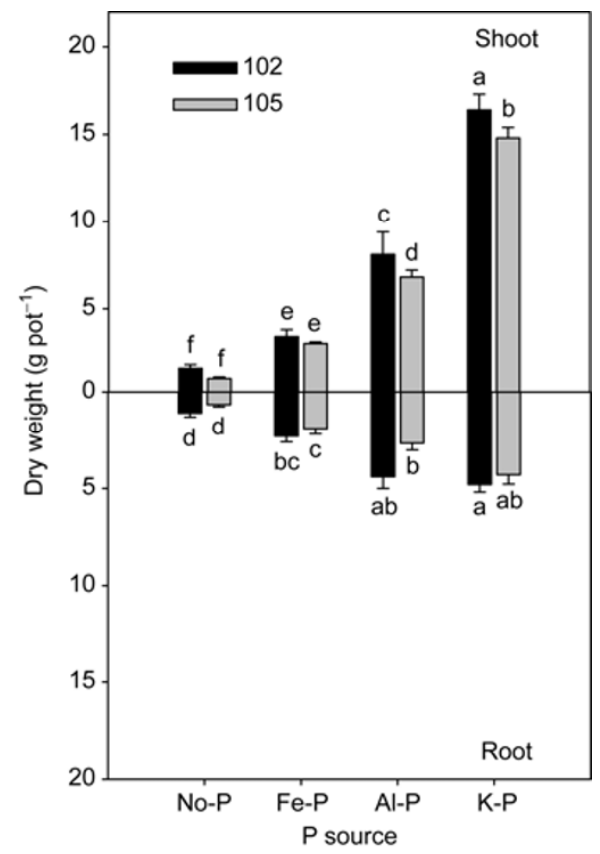

Figure 1 Shoot and root dry weight of two rapeseed genotypes supplied with different $\mathrm{P}$ sources $45 \mathrm{~d}$ after sowing. Error bars represent standard errors of the means of four replicates. Different letters indicate statistical difference at $P<0.05$ between genotypes among all $\mathrm{P}$ treatments. 
grown under the K-P treatment $(P<0.05)$. The $\mathrm{pH}$ of the plant rhizosphere under the no-P treatment did not change during the experiment (Figure 3). There was no genotypic

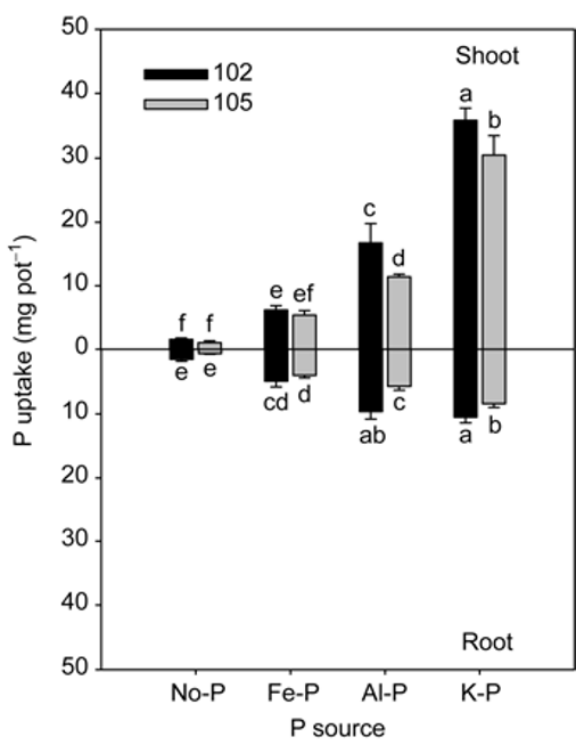

Figure 2 Shoot and root $\mathrm{P}$ uptake of two rapeseed genotypes supplied with different $\mathrm{P}$ sources $45 \mathrm{~d}$ after sowing. Error bars represent standard errors of the means of four replicates. Different letters indicate statistical difference at $P<0.05$ between genotypes among all $\mathrm{P}$ treatments.

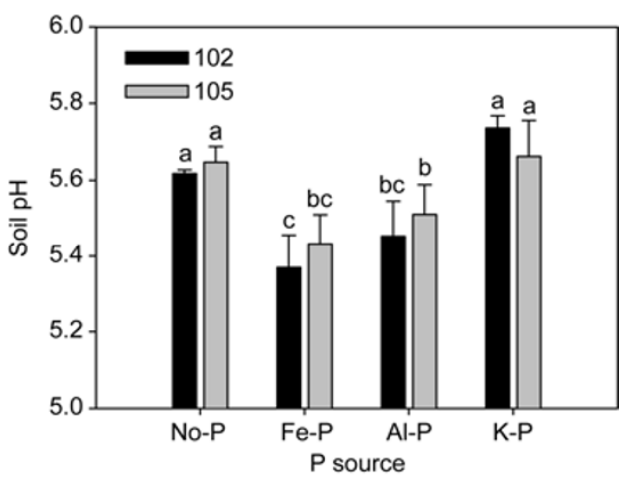

Figure $3 \mathrm{pH}$ of rhizosphere soil of two rapeseed genotypes supplied with different $\mathrm{P}$ sources $45 \mathrm{~d}$ after sowing. Error bars represent standard errors of the means of four replicates. Different letters indicate statistical difference at $P<0.05$ between genotypes among all $\mathrm{P}$ treatments. difference in rhizosphere soil $\mathrm{pH}$ when plants were supplied with two different sparingly soluble P sources (Figure 3).

\subsection{Soil-available $P$ and concentration of inorganic $P$ in the rhizosphere}

The concentration of available $\mathrm{P}$ in the rhizosphere of both genotypes increased progressively from the no-P treatment to the Al-P, Fe-P, and K-P treatments (Table 1). Moreover, the available $\mathrm{P}$ concentration in the rhizosphere soil of the P-efficient genotype 102 was lower than that of the P-inefficient genotype 105 under all P treatments, especially when plants were supplied with sparingly soluble P sources $(P<0.05)$ (Table 1).

The concentrations of both Al-P and Fe-P in the rhizosphere soil were higher for both rapeseed genotypes supplied with different $\mathrm{P}$ sources after $45 \mathrm{~d}$ growth, compared with those in the control treatment (no P) (Table 1). It appeared that Al-P was utilized more easily than Fe-P. There was a significant difference between the two genotypes in the concentration of Al-P, but not Fe-P, in the rhizosphere soil $(P<0.05)$. There was a significant decrease in the concentration of $\mathrm{Ca}-\mathrm{P}$ in the rhizosphere soil of both genotypes. In addition, there were significant differences between the two genotypes in amount of available $\mathrm{P}$ in the rhizosphere of plants supplied with Al-P and Fe-P, but not K-P (Table 1).

\subsection{Root morphological traits in the solution experi- ment}

There were significant differences in biomass weight and root morphology among the different $\mathrm{P}$ treatments and between the two genotypes (Table 2). Both genotypes showed greater shoot biomass under the high-P treatment than under the low-P treatment, while the opposite trend was observed for root biomass. P-stressed plants showed significantly increased total root length, root surface area, and root volume, and significantly more lateral roots compared with plants grown under the high-P treatment $(P<0.05)$. We observed wide genotypic variation in root morphological characteristics between the two genotypes under low-P conditions. The P-efficient genotype 102 developed more

Table 1 Soil-available $\mathrm{P}$ and inorganic $\mathrm{P}$ fraction concentrations in rhizospheres of two rapeseed genotypes supplied with different $\mathrm{P}$ sources $45 \mathrm{~d}$ after sowing. Different letters indicate statistical difference at $P<0.05$ between genotypes in each $\mathrm{P}$ treatment $(n=4)$

\begin{tabular}{|c|c|c|c|c|c|}
\hline \multirow{2}{*}{ Genotype } & \multirow{2}{*}{ P source } & \multirow{2}{*}{ Available $\mathrm{P}$ (mg P kg${ }^{-1}$ soil) } & \multicolumn{3}{|c|}{ Inorganic $\mathrm{P}$ fractions (mg $\mathrm{P} \mathrm{kg}^{-1}$ soil) } \\
\hline & & & $\mathrm{Al}-\mathrm{P}$ & $\mathrm{Fe}-\mathrm{P}$ & $\mathrm{Ca}-\mathrm{P}$ \\
\hline \multirow[t]{3}{*}{102} & No-P & $3.74 \mathrm{~d}$ & $2.42 \mathrm{~d}$ & $62.2 \mathrm{~d}$ & $14.2 \mathrm{~b}$ \\
\hline & $\mathrm{Fe}-\mathrm{P}$ & $4.75 \mathrm{bc}$ & $3.98 \mathrm{~cd}$ & $80.0 \mathrm{ab}$ & $8.2 \mathrm{f}$ \\
\hline & $\mathrm{K}-\mathrm{P}$ & $7.36 \mathrm{a}$ & $6.54 \mathrm{ab}$ & $74.8 \mathrm{c}$ & $15.0 \mathrm{ab}$ \\
\hline \multirow[t]{3}{*}{105} & No-P & $4.23 \mathrm{~cd}$ & $2.48 \mathrm{~d}$ & $64.2 \mathrm{~d}$ & $15.3 \mathrm{a}$ \\
\hline & $\mathrm{Fe}-\mathrm{P}$ & $6.77 \mathrm{a}$ & $6.12 \mathrm{~b}$ & $83.5 \mathrm{a}$ & $9.9 \mathrm{e}$ \\
\hline & $\mathrm{K}-\mathrm{P}$ & $7.59 \mathrm{a}$ & $6.85 \mathrm{ab}$ & $74.0 \mathrm{c}$ & $15.5 \mathrm{a}$ \\
\hline
\end{tabular}


dominant root morphological traits than the P-inefficient genotype $105(P<0.05)$ (Table 2$)$.

\subsection{Flux of $\mathrm{H}^{+}$from roots, $\mathrm{H}^{+}$-ATPase activity in roots, and rhizosphere acidification}

Under the high-P treatment, roots of both genotypes showed little proton flux, and there was no significant difference between the genotypes (Figure 4A). However, P deficiency resulted in increased proton flux from the roots, and the P-efficient genotype 102 showed greater proton flux than the P-inefficient genotype 105 (Figure 4A). In addition, under low-P conditions, $\mathrm{H}^{+}$-ATPase activity was significantly increased in roots of genotype 102 but not genotype
105. Overall, the activity of $\mathrm{H}^{+}$-ATPase in the roots was greater in the P-efficient genotype 102 than in the P-inefficient genotype 105 (Figure 4B).

For the two genotypes, the acidification of the rhizosphere under low-P or high-P conditions was visible as color changes in the agar gel on the 18th day after transfer (Figure 5). Under high-P conditions, the color of the agar gel in the rhizosphere was almost unchanged for both genotypes (Figure 5A and B). However, the agar gel became yellow under low-P conditions (Figure 5C and D), reflecting acidification of the rhizosphere under P-deficient conditions. The deeper yellow color of the agar gel indicated that the acidification of the rhizosphere was stronger for the P-efficient genotype 102 than the P-inefficient genotype

Table 2 Dry weights and root morphological parameters of P-efficient genotype 102 and P-inefficient genotype 105 after $18 \mathrm{~d}$ growth in low-P $\left(5 \mu\right.$ mol $\mathrm{L}^{-1}$ $\mathrm{P})$ or high-P $\left(1 \mathrm{mmol} \mathrm{L}{ }^{-1} \mathrm{P}\right)$ nutrient solutions. Different letters indicate statistical significance at $P<0.05(n=3)$

\begin{tabular}{|c|c|c|c|c|c|c|c|}
\hline Treatment & Genotype & $\begin{array}{c}\text { Shoot dry weight } \\
(\mathrm{mg})\end{array}$ & $\begin{array}{l}\text { Root dry weight } \\
(\mathrm{mg})\end{array}$ & $\begin{array}{c}\text { Total length } \\
(\mathrm{cm})\end{array}$ & $\begin{array}{c}\text { Surface area } \\
\left(\mathrm{cm}^{2}\right)\end{array}$ & $\begin{array}{c}\text { Root volume } \\
\left(\mathrm{cm}^{3}\right)\end{array}$ & $\begin{array}{l}\text { Number of } \\
\text { lateral root }\end{array}$ \\
\hline \multirow{2}{*}{ High $\mathrm{P}$} & 102 & $66.9 \mathrm{a}$ & $7.6 \mathrm{a}$ & $214 b$ & $12.4 \mathrm{~b}$ & $0.058 \mathrm{c}$ & $1376 \mathrm{~b}$ \\
\hline & 105 & $38.6 \mathrm{bc}$ & $3.5 \mathrm{~b}$ & $140 \mathrm{~d}$ & $6.3 c$ & $0.030 \mathrm{~d}$ & $834 \mathrm{c}$ \\
\hline Low $\mathrm{P}$ & 105 & $23.1 \mathrm{c}$ & $4.9 \mathrm{~b}$ & $168 \mathrm{c}$ & $12.4 \mathrm{~b}$ & $0.076 \mathrm{~b}$ & $1270 \mathrm{~b}$ \\
\hline
\end{tabular}

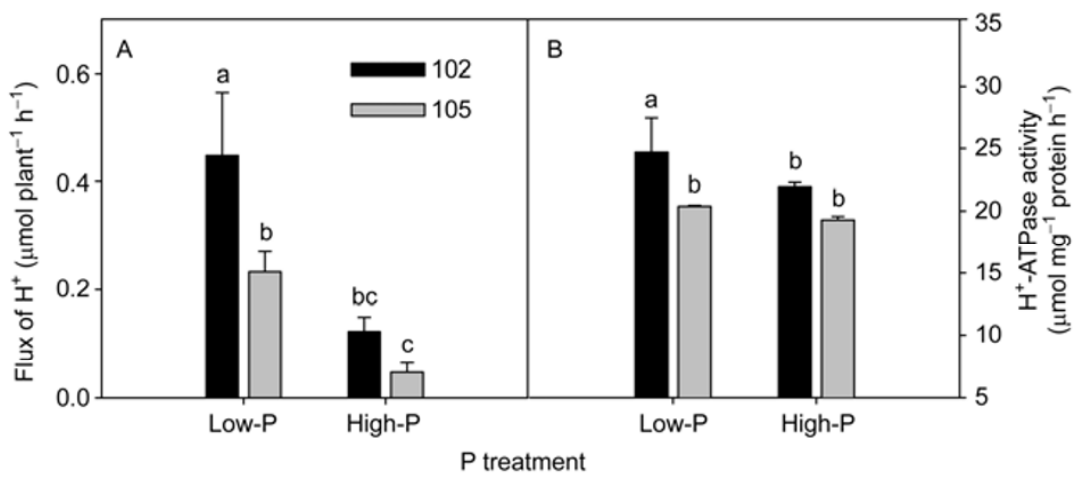

Figure 4 Flux of $\mathrm{H}^{+}$and $\mathrm{H}+-\mathrm{ATPase}$ activity in roots of two genotypes of rapeseed grown in low-P $\left(5 \mu \mathrm{mol} \mathrm{L} \mathrm{L}^{-1} \mathrm{P}\right)$ and high-P $\left(1 \mathrm{mmol} \mathrm{L}^{-1} \mathrm{P}\right)$ nutrition solutions during the treatment period $(18 \mathrm{~d})$. Values are the means of three replicates $\pm \mathrm{SD}$ at $P<0.05$. Different letters indicate statistical difference at $P<0.05$ between genotypes and $\mathrm{P}$ treatments.

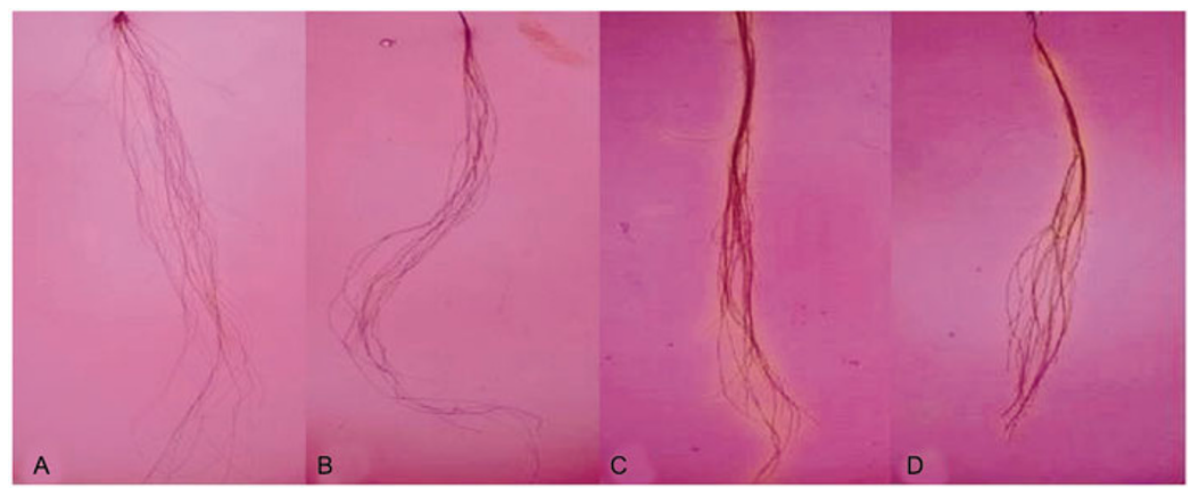

Figure 5 Visualization of rhizosphere acidification of two rapeseed genotypes 18 days after transfer into low-P $\left(5 \mu \mathrm{mol} \mathrm{L}{ }^{-1} \mathrm{P}\right)$ and high-P $\left(1 \mathrm{mmol} \mathrm{L}^{-1} \mathrm{P}\right)$ treatments. High P-treatment of genotypes 102 (A) and 105 (B), and low-P treatment of genotypes 102 (C) and 105 (D). Roots were imbedded for 5 h in agar

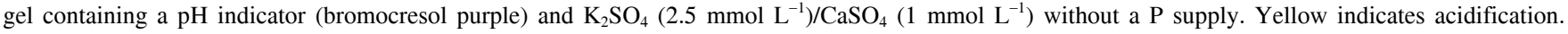
Changes in $\mathrm{pH}$ are indicated by color changes. 
105 (Figure 5C and D).

\subsection{Root exudation of carboxylates}

We quantified tartrate, malate, acetate, citrate, and succinate in the root exudates of two genotypes (Figure 6). Large amounts of carboxylates were exuded from the roots of the two genotypes under low-P and no-P treatments. Under high $\mathrm{P}$ conditions, only small amounts of carboxylates were exuded by the plants, and there were no significant differences between the genotypes. In contrast, in the no-P solution, both genotypes released large amounts of carboxylates (Figure 6A). Malic and acetic acids were the predominant carboxylates exuded by the P-stressed genotypes (Figure 6B and $\mathrm{C}$ ). There was no significant difference in the amount of total carboxylates released between the low-P and no-P treatments, despite the lower concentrations of malate and citrate released by roots under the low-P treatment compared with those under the no-P treatment. The P-efficient genotype 102 released a significantly larger amount of total carboxylates than the P-inefficient genotype 105 under the no-P treatment but not under the low-P treatment (Figure $6 \mathrm{~A})$.

\section{Discussion}

Low $\mathrm{P}$ availability has seriously limited plant productivity in acidic soils. However, it has been reported that there is wide genotypic variation in the utilization of sparingly soluble $\mathrm{P}$ among plant species and genotypes [26-28]. The results obtained in the present study show that genotype 102 was more P-efficient because it was able to produce up to $59 \%$ and $27 \%$ of its maximum dry weight when supplied with Al-P and Fe-P, respectively, whereas genotype 105 produced only $49 \%$ and $25 \%$, respectively, of its maximum dry weight under the same conditions (Figure 1). This result supports our previous findings that genotype 102 had a higher rate of $\mathrm{P}$ uptake and growth in soils with low $\mathrm{P}$ availability [18]. These results suggest that there are different physiological or biological mechanisms between genotypes that contribute to the utilization of sparingly soluble P. These findings were further confirmed by the fact that genotype 102 could mobilize and uptake more P from the rhizosphere soil than genotype 105 , as demonstrated by analysis of the biomass production, $\mathrm{P}$ uptake, and inorganic $\mathrm{P}$ fractions in the rhizosphere soil of both genotypes (Figure 2, Table 1).

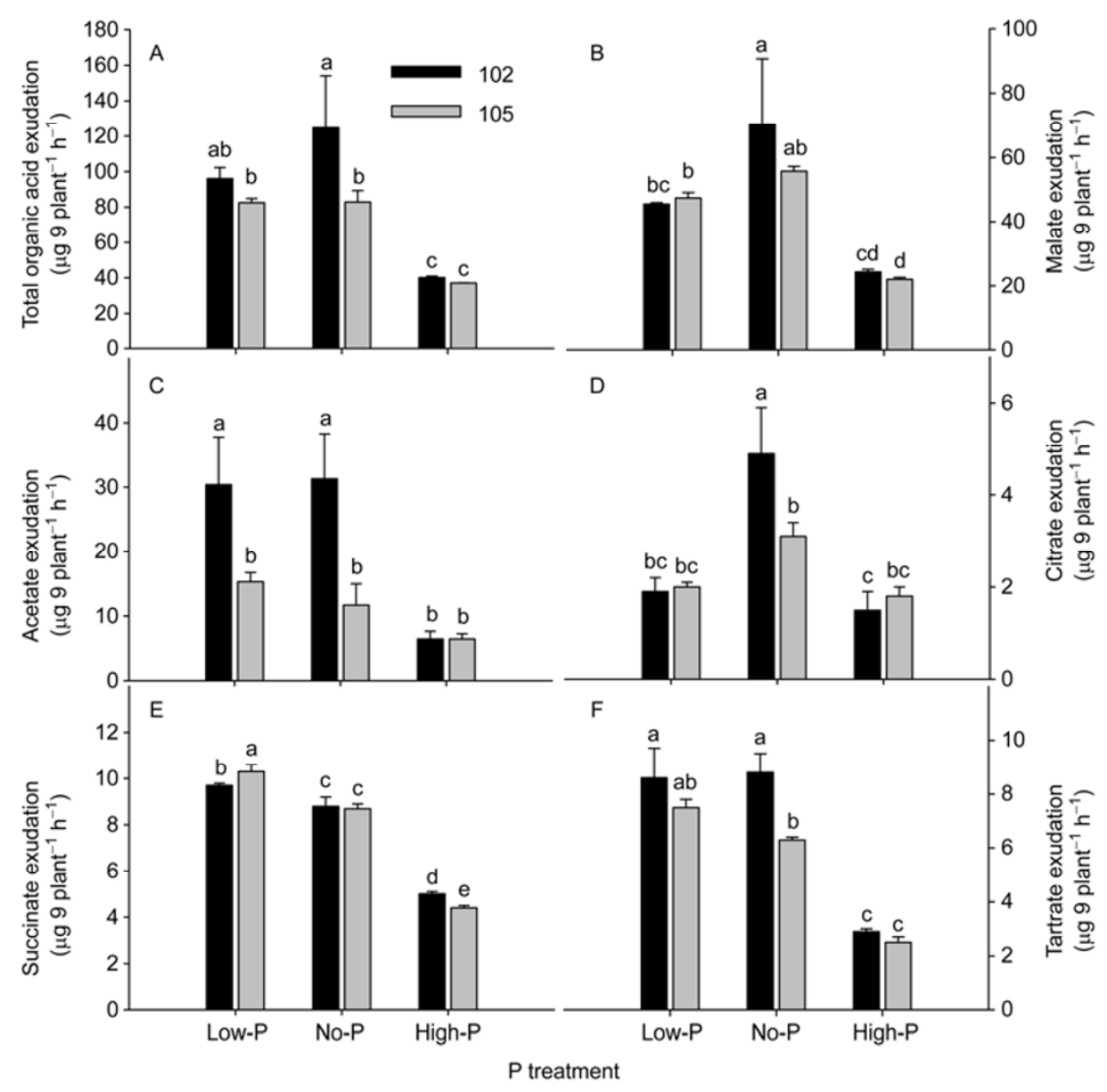

Figure 6 Genotypic variation in organic acid exudation of plants grown in low-P $\left(5 \mu m o l L^{-1} \mathrm{P}\right)$, no-P (without $\left.\mathrm{P}\right)$ and high-P $\left(1\right.$ mmol $\left.\mathrm{L}^{-1} \mathrm{P}\right)$ nutrient solutions during the 19-day treatment period. Values are means of three replicates $\pm \mathrm{SD}$ at $P<0.05$. Different letters indicate statistical difference at $P<0.05$ between genotypes and among $\mathrm{P}$ treatments. 
It is noteworthy that both genotypes were better able to utilize $\mathrm{P}$ from Al-P than from Fe-P, producing greater dry matter and accumulating higher levels of $\mathrm{P}$ in the tissues (Figures 1 and 2). We believe that there may be two reasons for this: First, Al-P is more soluble than Fe-P. Similar results were reported in other studies, which suggested that because of its poor solubility, Fe-P was less available to a wide range of crops than either Ca-P or Al-P [29,30]. Second, the higher $\mathrm{Al}$ concentration resulting from soil acidification under the Al-P treatment might stimulate the release of organic acid anions and indirectly supplement the Al-P nutrition compared to the Fe-P treatment [31,32]. As has been reported previously [33-35], in the presence of external Al, Al-resistant species or genotypes exude a number of organic anions including citrate, malate, and oxalate, and the exudation of citrate might contribute to the detoxification of $\mathrm{Al}$ and to the increased phosphate availability in the rhizosphere in rapeseed [36].

In the present study, the P-stressed genotypes released more $\mathrm{H}^{+}$and acidified their rhizosphere more intensely than those under high-P conditions (Figures 4A and 5). This may be explained by the increased activity of $\mathrm{H}^{+}$-ATPase in the roots of both genotypes under the low-P treatment (Figure 4B). This observation is consistent with results from Yan et al. [16], who suggested that the enhanced activity of the plasma membrane $\mathrm{H}^{+}$-ATPase in cluster roots of white lupin under P-stressed conditions might be responsible for the increased $\mathrm{H}^{+}$release. Rhizosphere acidification induced by P-stress can increase the availability of rock phosphate in neutral and alkaline calcareous soil [37,38]. Our results indicate that the $\mathrm{Ca}-\mathrm{P}$ in the rhizosphere soil was depleted significantly when Al-P and Fe-P, but not K-P, were added. In addition, the soil $\mathrm{pH}$ for both genotypes decreased significantly (Figure 3), suggesting that rhizosphere acidification in response to P-stress enhanced the solubilization of $\mathrm{Ca}-\mathrm{P}$ to meet plant growth requirements. The P-efficient genotype 102 , which released more $\mathrm{H}^{+}$than the $\mathrm{P}$-inefficient genotype 105, utilized more $\mathrm{Ca}-\mathrm{P}$ in the rhizosphere to achieve rapid plant growth under the Al-P and Fe-P treatments.

Earlier studies suggested that carboxylates exudation might be a physiological adaptation to $\mathrm{P}$ deficiency and may contribute to rhizosphere acidification $[39,40]$. In the present work, both genotypes secreted larger amounts of carboxylates under low-P conditions than under high-P conditions (Figure 6). In addition, the P-efficient genotype 102 exuded more carboxylates than the P-inefficient genotype under the no-P treatment but not under the low-P treatment (Figure 6A). These results indicate that not only an active mechanism but also a secondary root response, such as leakage of the plasma membrane, may be involved in stimulating organic acid exudation from roots under long-term $\mathrm{P}$ deficiency [25,41].

In some plant species, exudation of carboxylates can release $\mathrm{P}$ from sparingly soluble $\mathrm{Fe}$ and $\mathrm{Al}$ phosphate via lig- and exchange or chelation of metal ions [30,42]. Hoffland [13] and Garden et al. [43,44] suggested that carboxylates secreted by plant roots in the rhizosphere could increase $\mathrm{P}$ availability by mobilizing $\mathrm{P}$ from sparingly soluble $\mathrm{Ca}, \mathrm{Fe}$, and $\mathrm{Al}$ phosphates. Our results showed that the concentrations of Al-P and Fe-P in the rhizosphere soil of two rapeseed genotypes supplied with sparingly soluble $\mathrm{P}$ sources decreased significantly compared with their respective concentrations in rhizosphere soil of plants grown under a K-P treatment. In addition, there were significant genotypic differences in the concentration of Al-P when plants were supplied with two sparingly soluble $\mathrm{P}$ sources (Table 1). This indicates that the amount of carboxylates determines the ability of rapeseed genotypes to utilize sparingly soluble $\mathrm{Al}$ and Fe phosphates. The increased carboxylate secretion by the P-efficient genotype 102 meant that it was better able to release $\mathrm{P}$ from $\mathrm{Al}$ and $\mathrm{Fe}$ phosphates than the $\mathrm{P}$-inefficient genotype 105 (Table 1).

In P-deficient conditions, plants develop more lateral roots, and show increases in root length, root surface area, and root volume $[45,46]$. These changes significantly alter the root architecture and morphology. In this study, P-stressed plants showed significantly increased total root length, root surface area, and root volume, and developed more lateral roots compared with those grown under the high-P treatment (Table 2). The results are similar to those observed in previous studies as mentioned above. A larger root system is critical for $\mathrm{P}$ uptake by plants because $\mathrm{P}$ is relatively unavailable and immobile in many soils $[47,48]$. Root length, surface area, and volume are particularly important morphological characteristics for $\mathrm{P}$ acquisition, which requires the expansion of the rhizosphere to enhance uptake [49-51]. The present results show that the P-efficient genotype 102 developed more dominant root morphological traits than did the P-inefficient genotype 105 (Table 2). These changes allowed genotype 102 to increase $\mathrm{P}$ acquisition from the rhizosphere because of greater root-soil contact.

In some studies, the root length, surface area, and root exudations per unit root biomass were compared to show differences in P-efficiency among genotypes. A more developed root system and/or greater exudation of carboxylates per unit root biomass may contribute greatly to the P-use efficiency of plants. In the present study, there was little difference between the two cultivars in terms of carboxylates exudation per unit root biomass (data not shown). However, from the view point of practical production, $\mathrm{P}$ efficiency of plants in low-P soil is primarily related to total root exudation and dominant root morphology, which are more significant for P uptake from soil, and consequently, for plant yield. Our results show that the total root length, surface area, and root secretions were much higher for the P-efficient genotype 102 than for the P-inefficient genotype 105. These root characteristics may activate more of the sparingly soluble $\mathrm{P}$ in soils and indirectly stimulate plant 
growth.

The biomass and $\mathrm{P}$ uptake of plants grown in P-deficient soil are directly related to the ability of the plant to acquire $\mathrm{P}$ from sparingly soluble phosphates. In the present study, we found that there was significantly higher biomass dry weight and $\mathrm{P}$ accumulation for both genotypes under Al-P than under Fe-P treatment. Greater P uptake was also observed for the P-efficient genotype 102 than for the P-inefficient genotype 105 under Al-P treatment but not Fe-P treatment $(P<0.05)$ (Figure 2). Therefore, we presume, as described by Pearse et al. [52], that greater ability of plants to access one form of sparingly soluble phosphate does not mean that they can efficiently utilize all forms of sparingly soluble $\mathrm{P}$, and the ability to access different forms of $\mathrm{P}$ sources by plants may depend on different morphological and physiological mechanisms. In addition, as observed in the pot experiment, the sparingly soluble inorganic phosphate supplied to each treatment was not the sole $\mathrm{P}$ source. Organic phosphate in the soil can also be utilized after being mineralized by root-secreted phosphatases and microbes in the rhizosphere. Therefore, a combination of morphological and physiological mechanisms, including changes in root morphology and root exudates, can explain the genotypic differences in the utilization of different sparingly soluble $\mathrm{P}$ sources.

This work was supported by the National Basic Research Program of China (Grant No. 2011CB100301).

1 Holford I C R. Soil phosphorus: its measurement, and its uptake by plants. Aust J Soil Res, 1997, 35: 227-240

2 Gardner W K, Barber D A, Parbery D G. The acquisition of phosphorus by Lupinus albus L.: III. The probable mechanism by which phosphorus movement in the soil/ root interface is enhanced. Plant Soil, 1983, 70: 107-124

3 Hoffland E, Findenegg G R, Nelemans J A. Solubilization of rock phosphate by rape. II. Local root exudation of organic acids as a response to P-starvation. Plant Soil, 1989, 113: 161-165

4 Kamh M, Horst W J, Amer F, et al. Mobilization of soil and fertilizer phosphate by cover crops. Plant Soil, 1999, 211: 19-27

5 Asmar F, Gahoonia T S, Nielsen N E. Barley genotypes differ in activity of soluble extracellular phosphatase ad depletion of organic phosphorus in the rhizosphere soil. Plant Soil, 1995, 172: 117-122

6 Trolove S N, Hedley M J, Caradus J R, et al. Uptake of phosphorus from different sources by Lotus pedunculatus and three genotypes of Trifolium repens. I. Plant yield and phosphate efficiency. Aust J Soil Res, 1996, 34: 1015-1026

7 Ming F, Mi G H, Zhang F S, et al. Differential response of rice plants to low-phosphorus stress and its physiological adaptive mechanism. J Plant Nutr, 2002, 25: 1213-1224

8 Li Y F, Luo A C, Wei X H, et al. Genotypic Variation of rice in phosphorus acquisition from iron phosphate: Contributions of root morphology and phosphorus uptake kinetics. Russ J Plant Physiol, 2007, 54: 230-236

9 Akhtar M S, Oki Y, Adachi T. Genetic variability in phosphorus acquisition and utilization efficiency from sparingly soluble P-sources by Brassica cultivars under P-stress environment. J Agron Crop Sci, 2008, 194: 380-392

10 Ruiz L, Arvieu J C. Measurement of $\mathrm{pH}$ gradients in the rhizosphere. Symbiosis, 1990, 9: 71-75

11 Schjørring J K. Nitrate and ammonium absorption by plants growing at a sufficient or insufficient level of phosphorus in nutrient solution. Plant Soil, 1986, 91: 313-318

12 Hedley M J, Nye P H, White R E. Plant-induced changes in the rhizosphere of rape (Brassica napus cv. Emerald) seedlings. II. Origin of the $\mathrm{pH}$ change. New Phytol, 1982, 91: 31-44

13 Hoffland E, Boogaard R V D, Nelemans J, et al. Biosynthesis and root exudation of citric and malic acids in phosphate-starved rape plants. New Phytol, 1992, 122: 675-680

14 Lambers H, Juniper D, Cawthray G R, et al. The pattern of carboxylate exudation in Banksia grandis (Proteaceae) is affected by the form of phosphate added to the soil. Plant Soil, 2002, 238: 111-122

15 Kirk J G D, Du L V. Changes in rice root architecture, porosity, and oxygen and proton release under phosphorus deficiency. New Phytol, 1997, 135: 191-200

16 Yan F, Zhu Y Y, Müller C, et al. Adaptation of $\mathrm{H}^{+}$-pumping and plasma membrane $\mathrm{H}^{+}$-ATPase activity in proteoid roots of white lupin under phosphate deficiency. Plant Physiol, 2002, 129: 50-63

17 Föhse D, Claassen N, Jungk A. Phosphorus efficiency in plants. I. External and internal $\mathrm{P}$ requirement and $\mathrm{P}$ uptake efficiency of different plant species. Plant Soil, 1988, 110: 101-109

18 Zhang H W, Huang Y, Ye X S, et al. Genotypic differences in phosphorus acquisition and the rhizosphere properties of Brassica napus in response to low phosphorus stress. Plant Soil, 2009, 32: 91-102

19 Westerman R L. Soil Testing and Plant Analysis. 3rd ed. Madison: Soil Science Society of America, 1990

20 Bray R H, Kurtz L T. Determination of total, organic and available forms of phosphorus in soils. Soil Sci, 1945, 59: 39-45

21 Petersen G W, Corey R B. A modified Chang and Jackson procedure for routine fractionation of inorganic soil phosphates. Soil Sci Soc Am J, 1996, 30: 563-565

22 M'Sehli W, Youssfi S, Donnini S, et al. Root exudation and rhizosphere acidification by two lines of Medicago ciliaris in response to lime-induced iron deficiency. Plant Soil, 2008, 312: 151-162

23 Shen H, He L F, Sasaki T, et al. Citrate secretion coupled with the modulation of soybean root tip under aluminum stress. Up-regulation of transcription, translation, and threonine-oriented phosphorylation of plasma membrane $\mathrm{H}^{+}$-ATPase. Plant Physiol, 2005, 138: 287-296

24 Li L, Li S M, Sun J H, et al. Diversity enhances agricultural productivity via rhizosphere phosphorus facilitation on phosphorus-deficient soils. Proc Natl Acad Sci USA, 2007, 104: 11192-11196

25 Ishikawa S, Adu-Gyamfi J J, Nakamura T, et al. Genotypic variability in phosphorus solubilizing activity of root exudates by pigeonpea grown in low-nutrient environments. Plant Soil, 2002, 245: 71-81

26 Yan X L, Lynch J P, Beebe S E. Utilization of phosphorus substrates by contrasting common bean genotypes. Crop Sci, 1996, 36: 936-941

27 Jones D L, Darrah P R. Role of root derived organic acids in the mobilization of nutrients from the rhizosphere. Plant Soil, 1994, 166: 247-257

28 Johnson J F, Allan D L, Vance C P, et al. Root carbon dioxide fixation by phosphorus-deficient Lupinus albus L. Contribution to organic acid exudation by proteoid roots. Plant Physiol, 1996, 112: 19-30

29 Otani T, Ae N. Phosphorus (P) uptake mechanisms of crops grown in soils with low $\mathrm{P}$ states. I. Screening of crops for efficient $\mathrm{P}$ uptake. Soil Sci Plant Nutr, 1996, 42: 155-163

30 Shane M W, Lambers H, Cawthray G R, et al. Impact of phosphorus mineral source (Al-P or Fe-P) and $\mathrm{pH}$ on cluster-root formation and carboxylate exudation in Lupinus albus L. Plant Soil, 2008, 304: 169-178

31 Pearse S J, Veneklaas E J, Cawthray G R, et al. Triticum aestivum shows a greater biomass response to a supply of aluminium phosphate than Lupinus albus, despite releasing less carboxylates into the rhizosphere. New Phytol, 2006, 169: 515-524

32 Ryan P R, Delhaize E, Randall P J. Malate efflux from root apices and tolerance to aluminium are highly correlated in wheat. Aust $\mathrm{J}$ Plant Physiol, 1995, 22: 531-536

33 Delhaize E, Taylor P, Hocking P J, et al. Transgenic barley (Hordeum vulgare L.) expressing the wheat aluminium resistance gene (TaALMT1) shows enhanced phosphorus nutrition and grain produc- 
tion when grown on an acid soil. Plant Biotechnol J, 2009, 7: 391-400

34 Kochian L V, Hoekenga O A, Piñeros M A. How do crop plants tolerate acid soils? Mechanisms of aluminum tolerance and phosphorous efficiency. Annu Rev Plant Biol, 2004, 55: 459-493

35 Nian H, Ahn S J, Yang Z M, et al. Effect of phosphorus deficiency on aluminium- induced citrate exudation in soybean (Glycine max). Physiol Plant, 2003, 117: 229-236

36 Luo H M, Watanabe T, Shinano T, et al. Comparison of aluminium tolerance and phosphate absorption between rape (Brassica napus L.) and tomato (Lycopersicum esculentum Mill.) in relation to organic acid exudation. Soil Sci Plant Nutr, 1999, 45: 897-907

37 Zoysa A K N, Loganathan P, Hedley M J. Phosphorus utilization efficiency and depletion of phosphate fractions in the rhizosphere of three tea (Camellia sinensis L.) clones. Nutr Cycl Agroecosys, 1999, 53: 189-201

38 Keerthisinghe G, Hocking P J, Ryan P R, et al. Effect of phosphorus supply on the formation and function of proteoid roots of white lupin (Lupinus albus L.). Plant Cell Environ, 1998, 21: 467-478

39 Li M, Shinano T, Tadano T. Distribution of exudates of lupin roots in the rhizosphere under phosphorus deficient conditions. Soil Sci Plant Nutr, 1997, 43: 237-245

40 Neumann G, Massonneau A, Martinoia E, et al. Physiological adaptations to phosphorus deficiency during proteoid root development in white lupin. Planta, 1999, 208: 373-382

41 Zhang F S, Ma J, Cao Y P. Phosphorus deficiency enhances root exudation of low-molecular weight organic acids and utilization of sparingly soluble inorganic phosphates by radish (Raghanus satiuvs L.) and rape (Brassica napus L.) plants. Plant Soil, 1997, 196: 261-264

42 Hinsinger P. How do plant roots acquire mineral nutrients? Chemical properties involved in the rhizosphere. Adv Agron, 1998, 64: 225-265

43 Gardner W K, Parbery D G, Barber D A. The acquisition of phos- phorus by Lupinus albus L. I. Some characteristics of the soil/root interface. Plant Soil, 1982, 68: 19-32

44 Gardner W K, Barber D A, Parbery D G. The acquisition of phosphorus by Lupinus albus L. III. The probable mechanism by which phosphorus movement in the soil/root interface is enhanced. Plant Soil, 1983, 70: 107-124

45 Anghinoni I, Barber S A. Phosphorus influx and growth characteristics of corn roots as influenced by phosphorus supply. Agron J, 1980, 72: $685-688$

46 Schenk M K, Barber S A. Phosphate uptake by corn as affected by soil characteristics and root morphology. Soil Sci Soc Am J, 1979, 43: 880-883

47 Barber S A, Silberbush M. Plant root morphology and nutrient uptake. Am Soc Agron, 1984, 49: 65-87

48 Atkinson D. Influence of root system morphology and development on the need for fertilizers and the efficiency of use. In: Waisel Y, Eshel A, Kafkaki U, eds. Plant Roots: the Hidden Half. New York, Basel, Hong Kong: Marcel Dekder, Inc., 1991. 411-451

49 Leon J, Schwang K U. Description and application of a screening method to determine root morphology traits of cereal cultivars. Z Acker Pflanzenbau, 1992, 169: 128-134

50 Bouma T J, Nielsen K L, Kousttaal B. Sample preparation and scanning protocol for computerised analysis of root length and diameter. Plant Soil, 2000, 218: 185-196

51 Gahoonia T S, Nielsen N E. The effect of root induced $\mathrm{pH}$ changes on the depletion of inorganic and organic phosphorus in the rhizosphere. Plant Soil, 1992, 143: 185-191

52 Pearse S J, Veneklaas E J, Cawthray G, et al. Carboxylate composition of root exudates does not relate consistently to a crop species' ability to use phosphorus from aluminium, iron or calcium phosphate sources. New Phytol, 2007, 173: 181-190

Open Access This article is distributed under the terms of the Creative Commons Attribution License which permits any use, distribution, and reproduction in any medium, provided the original author(s) and source are credited. 